\title{
The Living Dead and the Practice of Landscape Restoration
}

\author{
Steven N. Handel
}

E cology and evolution are historical sciences; the patterns around us mesh current interactions with past events. Consequently, today's habitats are the products of species' adaptations, the forces that are molding our current landscapes, and long-gone events that have brought today's species mixes forward to us. This includes single species presence and abundance (we are rarely at equilibrium), but also the species' contemporary interactions that are necessary for reproduction and dispersal. Restoring species would be oh-so-easy if we could just identify the plant palette, install, and wait for the associated animals and microbes to appear from the landscape, like an ecological Santa on his biodiversity sled.

This does not happen. This is an old story. Elimination of required mutualists through extinction or habitat disturbances (by humans or other causes) can cause local populations to shrivel. Either they cannot reproduce at a level where birth rates match death rates, or dispersal to new microsites becomes too infrequent and local populations disappear. In our scrambled world of biodiversity, non-native species are enormous stressors, pushing out the effective, historical mutualists from long-lasting community dynamics.

Signs of species that have lost their historical mutualists and other community interactions are everywhere. Here in eastern North America, we have Osage oranges (Maclura pomifera) that lack the large herbivores (giant ground sloths?) that dispersed the huge fruits; smaller mammals chew fruits and disperse seed but produce very different seed shadows. Honey locust trees (Gleditsia triacanthos) have long branched thorns; they may have been useful against large Pleistocene herbivores, now gone, but our small mammals use them as ladders when climbing to eat the developing sweet fruits. The "living dead" label refers to the species that suffer because they can't reproduce without the right partners. The plants can be large and green, but the next cohort of seedlings may be rare or non-existent. Like the zombies of pop movies, they seem to stay alive but with no normal road to reproductive success.

Ecological Restoration Vol. 37, No. 3, 2019

ISSN 1522-4740 E-ISSN 1543-4079

( 2019 by the Board of Regents of the University of Wisconsin System.
Plants with features like these large fruits and thorns are not hopeless. Other sympatric species, some non-native, can form guilds that continue to pollinate, disperse, and defend, even if they played no role in local evolutionary history. Non-native pollinators can visit flowers of many plant species, replacing native pollinators that may be locally extirpated. Small mammals can take bites from Osage oranges, and some ingested seeds could be dispersed away from the mother plant. Slow and steady frugivory can replace the big gulp of our missing Ice Age neighbors. Starlings (Sturnus vulgaris), a very common but European bird in North America, can disperse thousands of tree seeds, replacing the once common dispersers such as thrushes (family Muscicapidae) who now are very uncommon because of forest destruction throughout their range. The new food web works in a fashion as new partners take over the role of past ones. Ecological love rekindled, if you will.

We are surrounded by new interactions replacing the historical ones and sometimes the new partnerships allow persistence of the associated species, despite the ahistorical nature of the relationship. In island biology, we find "disharmonies," community structures that lack a clear analog in ancestral, continental ecological habitats. Our whole continental world, now beset with climate change, nonnative species pools, and fragmentation may be becoming a supersized island, with new interactions determining the winners and losers of the demographic races. Additionally, the extinction of specialist mutualists as habitats shrink and become isolated cut metapopulation processes, hastening species loss.

The dead may live again in our changing habitats, as these new interactions allow some species to persist. But how does this effect our restoration practices? We still try to match our species lists in a restoration project with reasonable nearby or recent past community species richness. The unknown presence and abundance of local mutualists in this changed world may be addressed by doing an environmental gamble and increasing the diversity in our initial palettes and constructed habitat zones. Introducing more plant species may be spinning an ecological roulette wheel, giving us more chances to create partnerships that will do the demographic job of sustaining populations on our projects. 
We are ignorant of all the species interactions we now have, some new, some old. But we know that even more changes will be occurring as the biotic and physical conditions of landscapes continue to change. Greater species richness at the beginning of a restoration project may be the ecological insurance to overcome the lack of historical interactions that once were needed to maintain ecological structure and function. Putting more bets on our restoration roulette wheel can ensure that sometimes our projects win. They persist. We can think of this approach as multiple guesses on a restoration multiple choice test. Eventually you may pass. Restoration success, albeit defined by an atypical community functioning, may be produced.

\section{Recommended Readings}

Dick, C.W. 2001. Genetic rescue of remnant tropical trees by an alien pollinator. Proceedings of the Royal Society of London. Series B: Biological Sciences. 268:2391-2396.
Ehrlich, P.R. 2017. What should conservation biologists be doing? An homage to Ilkka Hanski. In Annales Zoologici Fennici. 54:7-12.

Guimarães Jr, P.R., Galetti, M. and Jordano, P. 2008. Seed dispersal anachronisms: rethinking the fruits extinct megafauna ate. PloS One 3(3):e1745.

Janzen, D.H. 2001. Latent extinctions-the Living Dead. Pages 689-699 in Levin, S.A. (ed). Encyclopedia of Biodiversity, vol. 3. New York, NY: Academic Press.

Rumeu, B., Devoto, M., Traveset, A., Olesen, J.M., Vargas, P., Nogales, M. and Heleno, R., 2017. Predicting the consequences of disperser extinction: richness matters the most when abundance is low. Functional Ecology 31:1910-1920.

Soga, M., Yamaura, Y. and Koike, S., 2013. From ecological pessimism to conservation chance: reviving living dead in changing landscapes. Animal Conservation 16:16-18.

Valiente-Banuet, A., M.A. Aizen, , J.M.Alcántara, J. Arroyo, A. Cocucci, M. Galetti, et al. 2015. Beyond species loss: the extinction of ecological interactions in a changing world. Functional Ecology 29:299-307.

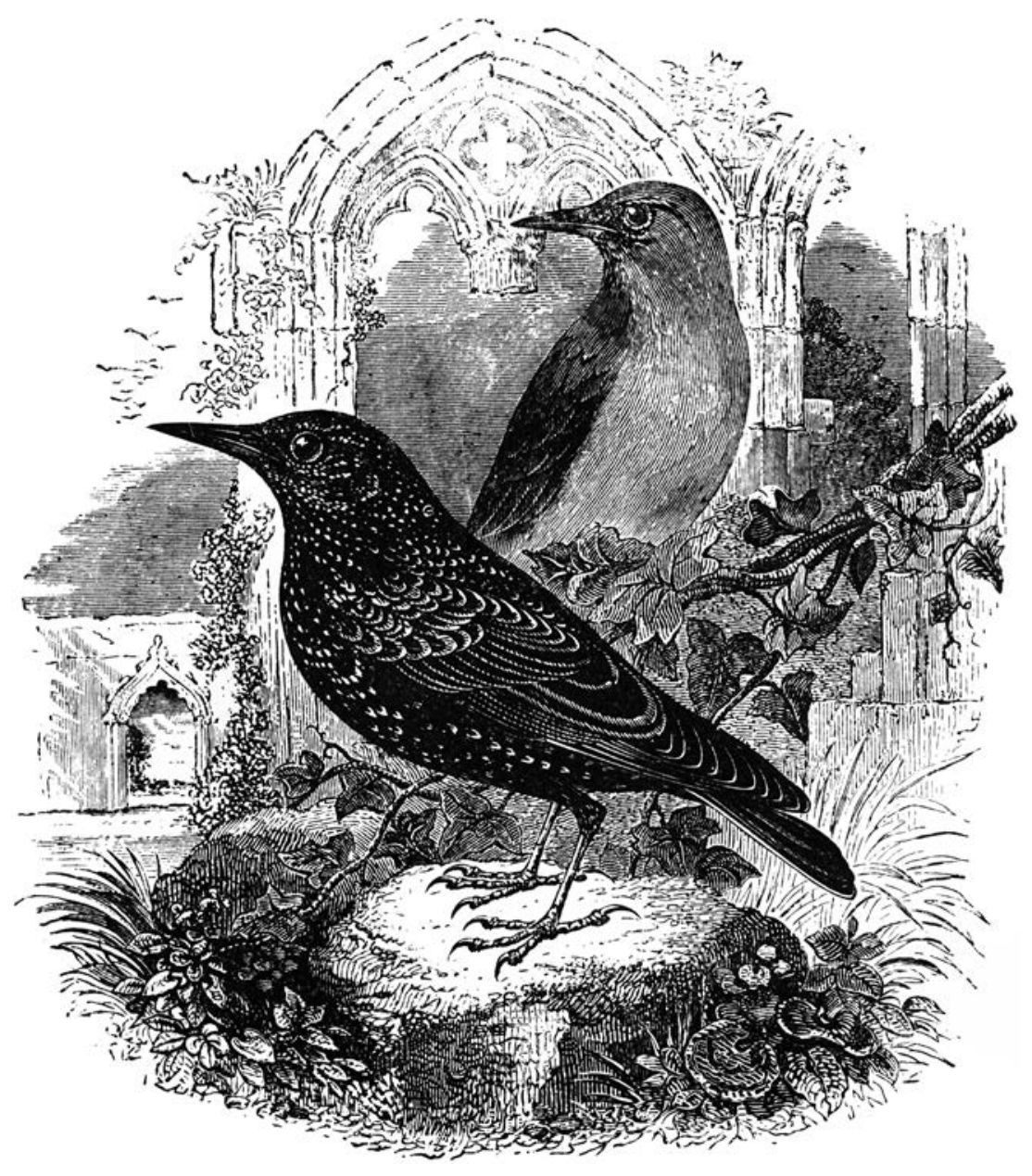

European Starlings. Goodrich, S.G. 1859. Animal Kingdom Illustrated Vol 2. New York, NY: Derby \& Jackson. The Florida Center for Instructional Technology, fcit.usf.edu. 